\title{
ANÁLISE COMPARATIVA DA LINGUAGEM ORAL DE CRIANÇAS OUVINTES E SURDAS USUÁRIAS DE IMPLANTE COCLEAR
}

\section{Comparative of verbal language analysis of listeners children and deaf children with cochlear implant}

\author{
Carla Aparecida de Urzedo Fortunato ${ }^{(1)}$, Maria Cecília Bevilacqua (2), \\ Maria da Piedade Resende da Costa ${ }^{(3)}$
}

\begin{abstract}
RESUMO
Objetivo: analisar e comparar a expressão verbal de crianças ouvintes e crianças usuárias de implante coclear. Métodos: os participantes foram 12 crianças ouvintes, entre 4 anos e 2 mês e 4 anos e 11 meses, e 10 crianças portadoras de perda auditiva neurossensorial profunda, usuárias de implante coclear, de 4 anos e 3 meses a 5 anos e 0 meses. As crianças foram avaliadas por meio da Escala de Expressão Verbal da Reynell Developmental Language Scales (RDLS), versão americana, adaptada por Fortunato-Queiroz (2007). Os dados dos dois grupos de crianças foram analisados e comparados entre si. Resultados: as crianças surdas obtiveram um desempenho inferior ao das crianças ouvintes quanto à expressão verbal. Três crianças implantadas obtiveram resultados próximos ao considerado como padrão pela pesquisa, ou seja, aos resultados das crianças ouvintes. Conclusão: os resultados obtidos pelas crianças deficientes auditivas, usuárias de IC, foram inferiores aos seus pares ouvintes. As crianças surdas que apresentaram as maiores pontuações foram as que possuíam maior tempo de uso do IC e menor tempo de privação sensorial.
\end{abstract}

DESCRITORES: Implante Coclear; Desenvolvimento da Linguagem; Surdez

\section{INTRODUÇÃO}

A linguagem é a capacidade de abstrair e simbolizar os signos linguísticos de forma significativa e contextualizada. Ela é essencial para a interação dos homens entre si e imprescindível para que o processo de comunicação se estabeleça. Pode-se dizer que a linguagem é constituída de três componentes (Forma, Conteúdo e Uso). O componente "Forma" abrange os aspectos que conferem estrutura à língua. Diz respeito ao modo como os sons são combinados para formar as palavras e as

(1) Fonoaudióloga; Pesquisadora do Centro de Pesquisas Audiológicas da Universidade de São Paulo, CPA/USP, Bauru, SP; Doutora em Educação Especial pela Universidade Federal de São Carlos.

(2) Fonoaudióloga; Professora Titular da Faculdade de Odontologia de Bauru da Universidade de São Paulo, FOB/USP, Bauru, SP; Livre-docente.

(3) Psicóloga; Professora do Programa de Pós-Graduação em Educação Especial da Universidade Federal de São Carlos, UFSCAR, São Carlos, SP; Mestre em Educação Especial; Doutora em Psicologia Experimental.

Conflito de interesses: inexistente palavras são combinadas para formar as frases. $\mathrm{O}$ componente "Conteúdo" refere-se ao sentido transmitido pelas palavras em frases, sentenças ou no discurso. Já o componente "Uso", inclui o propósito do falante direcionado para os outros (informar, solicitar, questionar) ou para si mesmo (raciocinar, auto-lembrar) ${ }^{1}$. É a interação entre forma, conteúdo e uso que constituem a linguagem normal. A linguagem pode ser expressa de várias formas, ou seja, é possível recorrer ou fazer uso de diferentes sistemas simbólicos, como desenhos, gestos, pintura. Todavia, a forma de utilização de linguagem mais peculiar é a falada ou oral, pois a mesma constitui uma forma de comunicação que capacita os seres humanos a transmitir informações com especificidade e detalhes ${ }^{2}$.

A linguagem oral envolve dois processos importantes: a Compreensão Verbal e a Expressão Verbal. A Compreensão Verbal precede a Expressão e, para que a mesma ocorra, é imprescindível que se tenha audição para fala. Verifica-se que qualquer prejuízo na audição interfere na compreensão verbal, bem como na formação e inter-relação de 
conceitos $e$, consequentemente na linguagem expressiva do indivíduo, afetando a comunicação verbal como um todo ${ }^{3}$.

Sabe-se que a deficiência auditiva pode ser caracterizada em diferentes tipos e graus, porém, a deficiência auditiva neurossensorial severa e/ou profunda é a que provoca maior prejuízo na aquisição e desenvolvimento da linguagem oral, podendo comprometer, consequentemente, o desempenho linguístico e acadêmico de crianças com este tipo e grau(s) de deficiência. Desta forma, a tecnologia tem disposto algumas alternativas para minimizar os efeitos da deficiência auditiva sobre a linguagem oral.

O implante coclear (IC) é atualmente o recurso tecnológico mais eficaz para favorecer o acesso da pessoa surda ao mundo sonoro. Até então nenhum dispositivo eletrônico havia possibilitado à pessoa que adquiriu surdez severa/profunda antes da aquisição da linguagem, a capacidade de compreendêla e expressá-la com funcionalidade e abstração, uma vez que o IC permite que ao surdo severo/profundo ouvir não apenas aos sons ambientais, mas também os sons da fala ${ }^{4,5}$. Trata-se de uma prótese auditiva computadorizada inserida cirurgicamente na orelha interna e que substitui parcialmente as funções da cóclea. O mecanismo de funcionamento dos implantes cocleares ocorre na criação de um campo elétrico no interior da cóclea, com o objetivo de estimular as neurofibrilas acústicas que envolvem a base das células ciliadas do órgão de Corti, por meio de impulsos sonoros previamente transformados em estímulos elétricos ${ }^{6}$. Todos os implantes cocleares funcionam utilizando este mesmo princípio, ou seja, transformam o estímulo acústico em estímulo elétrico, estimulando diretamente as células gangliais que, por sua vez, substituem as células da orelha interna.

Várias pesquisas têm demonstrado a efetividade do IC na redução do impacto da surdez sobre o desenvolvimento da função auditiva e, consequentemente, da linguagem oral, particularmente em crianças implantadas precocemente ${ }^{7-9}$. A avaliação e follow-up das habilidades de linguagem destas crianças são importantes por diversos motivos, dentre eles, a verificação da efetividade do IC e do progresso do desempenho auditivo. É recomendada a aplicação de protocolos que possibilitem a documentação e análise sistemática da evolução da criança de forma a oferecer subsídios para a conduta terapêutica ${ }^{10-12}$

Uma das formas de investigar o benefício na linguagem de crianças implantadas é utilizar padrões de comparação. Isto pode se feito de três formas: 1) comparando o desempenho da criança com o seu próprio desempenho anterior; 2) comparando a linguagem da criança implantada com a de outras crianças com surdez profunda, não implantadas; e, 3) comparando o desempenho da linguagem de crianças implantadas com o seu desempenho dos seus pares ouvintes ${ }^{13}$. Esta última forma de comparação é particularmente importante ao se considerar o atual processo de educação inclusiva, que prioriza a inclusão de todas crianças com deficiência na rede regular de ensino. Nele, as crianças surdas estão e estarão enfrentando o desafio de se ajustar aos níveis de habilidades linguísticas apresentados por seus pares ouvintes na classe comum.

O objetivo desta pesquisa foi analisar e comparar a expressão verbal de crianças surdas usuárias de implante coclear e de crianças ouvintes da mesma faixa etária.

\section{MÉTODOS}

O estudo realizado foi do tipo longitudinal ou horizontal retrospectivo. Os participantes foram 12 crianças ouvintes (5 meninas e 7 meninos), entre 4 anos e 2 mês e 4 anos e 11 meses, considerado como grupo controle; e 10 crianças implantadas (5 meninas e 5 meninos), usuárias de implante coclear, de 4 anos e 3 meses a 5 anos e 0 meses. 0 tempo de privação sensorial ou surdez variou entre 2 e 4 anos e o tempo de uso do IC entre 7 meses e 2 anos e 8 meses (Tabela 2). Os critérios de inclusão para o grupo de crianças ouvintes foram: crianças sem alterações auditivas (audição normal) e sem alterações de linguagem da faixa etária de 4 a 5 anos e 0 meses. $O$ critério de inclusão para o grupo de crianças surdas foi: crianças com perda auditiva neurossensorial profunda, usuárias de implante coclear, com idade de 4 a 5 anos e 0 meses.

Os materiais utilizados foram: brinquedos, objetos e figuras. Utilizou-se filmadora somente com as crianças surdas para facilitar a análise dos dados.

O procedimento de coleta de dados constou da avaliação das crianças participantes por meio da Escala de Expressão (ou de Linguagem Expressiva) da Reynell Developmental Language Scales (RDLS), versão americana ${ }^{3}$. Todos os responsáveis pelas crianças assinaram o Termo de Consentimento Livre e Esclarecido autorizando sua participação.

A Escala de Expressão da RDLS é composta por três seções (Estrutura, Vocabulário e Conteúdo), sendo que cada uma delas avalia um aspecto da linguagem. As seções são compostas por itens que devem ser pontuados durante a aplicação do teste. A pontuação total da Escala é 67.

A seção "Estrutura" possui 21 itens, que englobam desde as primeiras vocalizações, consideradas precursoras da fala; bem como a existência de 
jargão ou mesmo de palavras e frases. Observase também se as crianças, que já formulam frases, fazem uso apropriado das estruturas sintáticas e dos tempos verbais. Cada item corresponde a um ponto. Esta seção é avaliada por meio de conversa espontânea da criança, podendo ser pontuada a partir das respostas dadas em outras seções do teste.

\section{Escala de Expressão: ESTRUTURA}

1. Vocalizações distintas de choro.

2. Um som de uma sílaba.

3. Dois sons diferentes de uma sílaba.

4. Quatro sons diferentes de uma sílaba que devem incluir consoantes.

5. Sons de duas sílabas

6. Balbucio de duas sílabas.

7. Uma palavra definida.

8. Jargão expressivo e padrões de entonação.

9. Vocabulário de no mínimo 2 ou 3 palavras.

10. Vocabulário de no mínimo 4 ou 6 palavras.

11. Vocabulário de no mínimo 6 para 12 palavras.

12. Combinações de palavras.

13. Vocabulário de 20 ou mais palavras.

14. Uso apropriado de pelo menos duas palavras distintas de substantivos e verbos.

15. Frases de três ou mais palavras.

16. Uso apropriado de pelo menos duas preposições.

17. Uso apropriado de pelo menos dois pronomes.

18. Uso apropriado de um ou mais verbos no tempo passado.

19. Uso apropriado de um ou mais verbos no tempo futuro.

20. Construção de orações maduras.

21. Uso de orações complexas.

\section{Total Estrutura:}

A seção "Vocabulário" possui 22 itens, incluídos em três subdivisões com dificuldades crescentes: nomear objetos concretos, nomear substantivos (no singular e no plural) e verbos em figuras, descrever palavras ou conceitos abstratos. Cada item dessa seção corresponde a um ponto.

\section{Escala de Expressão: VOCABULÁRIO}

OBJETOS (7 objetos - bola, colher, carro, boneca, pente, meia, xícara).

1. O que é isto (como é chamado)? (bola)

2. O que é isto (como é chamado)? (colher)

3. O que é isto (como é chamado)? (carro)

4. O que é isto (como é chamado)? (boneca)

5. O que é isto (como é chamado)? (escova)
6. O que é isto (como é chamado)? (meia)

7. O que é isto (como é chamado)? (xícara)

FIGURAS (7 figuras - cadeira, flor, janela, bebendo, cartas, homens, chovendo, molhando)

8. O quê é isto? (cadeira)

9. O quê é isto? (flor)

10. O quê é isto? (janela)

11. O quê ela está fazendo? (bebendo/tomando)

12. O quê são estas? (cartas/papéis)

13. O quê são estes? (homens)

14. O quê está acontecendo? (chovendo)

15. E o quê está acontecendo com a garota? (molhando/tomando chuva)

PALAVRAS (nenhum material é necessário)

16. O quê é uma maçã?

17. O quê é um livro?

18. O quê é um vestido?

19. O quê significa dormir?

20. O quê significa barulho?

21. O quê significa fome?

22. O quê significa frio?

\section{Total Vocabulário:}

A seção "Conteúdo" avalia o uso criativo da linguagem para a descrição de figuras ilustrativas. Por exemplo, mostra-se a figura de um homem fazendo compras e solicita-se "Fale-me sobre esta figura". A fala da criança deve ser anotada literalmente para análise posterior. Inicialmente, pode ser usada uma figura para treino e orientação da criança para a tarefa. Somente neste momento, poderão ser feitas questões do tipo "O quê está acontecendo?", "O quê ele/ela está fazendo?", "O quê mais está acontecendo?", a fim de se direcionar as respostas que a criança deverá dar para as outras figuras (a resposta da figura de treino não deverá ser pontuada). Para as figuras posteriores as questões de direcionamento devem ser evitadas e somente a primeira ordem ("Fale-me sobre esta figura") deve ser dada. Três aspectos da expressão são pontuados:

a) Pontuação Basal (A e B) - Basal A: a resposta deve conter no mínimo uma referência para uma característica específica da figura (por exemplo, uma pessoa/objeto ou característica dos mesmos); Basal B: a resposta deve conter no mínimo uma referência da figura como um todo, ou seja, uma descrição geral da figura (por exemplo, "ele está fazendo compras"). Cada item apresentado corresponde a um ponto e, portanto, dois pontos são fornecidos para pontuação basal;

b) Ideias Conectadas (A, B, C e D): A - para este item ser pontuado deve haver pelo menos 
duas ideias conectadas dentro da sentença que contém a maioria das ideias; B - deve haver três ideias conectadas na sentença que contém a maioria das ideias; $\mathrm{C}$ - deve haver quatro ideias conectadas dentro da sentença que contém a maioria das ideias e, D - deve haver cinco ou mais ideias conectadas dentro da sentença que contém a maioria das ideias. Uma sentença nesta seção é definida como uma sequência simples de interrelação de ideias e, uma ideia é definida como um substantivo (um nome usado como sujeito ou objeto) ou um verbo. Cada item corresponde a um ponto e para que uma conexão de ideias $D$, por exemplo, seja pontuada, as anteriores (A, $B$ e C) também devem ter sido. Um exemplo: "Pessoas plantando flores" - inclui três ideias (pessoas, plantando, e flores). Portanto, Ideias Conectadas A e B são pontuadas (o que equivale a 2 pontos). A frase "Ele ajuda ela", por exemplo, não deve ser creditada neste item, pois contém apenas a ideia "ajuda";

c) Sentenças Adicionais (A e B): A - equivale a uma sentença adicional e, $B$ - equivale a duas ou mais sentenças adicionais. As sentenças adicionais são as outras sentenças que não foram pontuadas no item anterior (já que nas ideias conectadas somente se analisa a sentença que tem o maior número de ideias). Cada item descrito equivale a um ponto.

Nesta terceira seção da Escala de Linguagem Expressiva serão apresentadas três figuras, o que corresponde a uma pontuação máxima de 24 .

\section{Escala de Expressão: CONTEÚDO}

4 figuras - lavando pratos, colocando a mesa, fazendo compras, trabalhando no jardim

1. Lavando pratos (para treino apenas)

2. Colocando a mesa

Primeira resposta:

Resposta após ajuda simples:

\section{Fazendo compras}

4. Trabalhando no jardim

\section{Total Conteúdo:}

O projeto desta pesquisa foi encaminhado ao Comitê de Ética em Pesquisa da instituição, tendo sido aprovado pelo mesmo (Protocolo No.068/2002).
Os resultados encontrados foram analisados de forma qualitativa. Os dados obtidos com as crianças surdas foram comparados com os obtidos com as crianças ouvintes, considerados neste trabalho como o padrão de normalidade, já que a RDLS ainda não foi padronizada em crianças brasileiras. Os resultados das avaliações foram analisados em cada grupo de crianças (ouvintes e surdas) separadamente e, posteriormente, comparados entre si.

\section{RESULTADOS}

A Figura 1 apresenta as respostas obtidas pelos dois grupos de crianças, surdas usuárias de IC e ouvintes, para a seção "Estrutura" da Escala de Expressão Verbal da RDLS.

O gráfico mostrou que as crianças surdas fizeram uso, ou seja, expressaram todas as habilidades verbais avaliadas dos itens 1 ao 11, assim como as crianças ouvintes. Dos itens 12 a 14, 80-90\% das crianças surdas também tiveram o desempenho exigido pelos itens, ou seja, a porcentagem de crianças surdas que acertaram esses itens foi muito próxima da porcentagem de crianças ouvintes. Os itens de 15 a 17, uma média de $50 \%$ das crianças surdas também expressaram as habilidades exigidas, porém com um resultado inferior ao obtido pelas crianças ouvintes, já que todas elas $(100 \%)$ acertaram os itens em questão. No item 18, obteve-se acerto de $100 \%$ das crianças surdas e $100 \%$ das crianças ouvintes, apesar da maioria das crianças surdas terem expressado verbos isolados (tempo verbal passado), diferentemente das crianças ouvintes que o expressaram em frases. No item 19 , somente $30 \%$ das crianças surdas expressaram a habilidade verbal exigida (uso de tempo verbal futuro), porém foi a partir desse item que as crianças ouvintes começaram a apresentar falhas (uma criança ouvinte falhou). Nos itens posteriores (20 e 21) houve acertos apenas de crianças ouvintes.

As Figuras 2, 3 e 4 mostram as respostas obtidas pelas crianças surdas usuárias de IC e crianças ouvintes, para a seção "Vocabulário", subteste Objetos, Figuras e Palavras, respectivamente.

Observando a Figura 2, nota-se que as crianças ouvintes acertaram todos os itens, com exceção dos itens 5 (escova) e 7 (xícara). As crianças surdas apresentaram o maior número de acertos (100\% e 90\%, respectivamente) para os itens 1 (bola) e 3 (carro), objetos mais comuns no cotidiano das crianças e, portanto, os mais facilmente adquiridos pelas mesmas em sua linguagem. $O$ maior número de falhas ocorreu nos itens: 5 (escova) e 7 (xícara), os quais apenas duas crianças surdas $(20 \%)$ acertaram. 


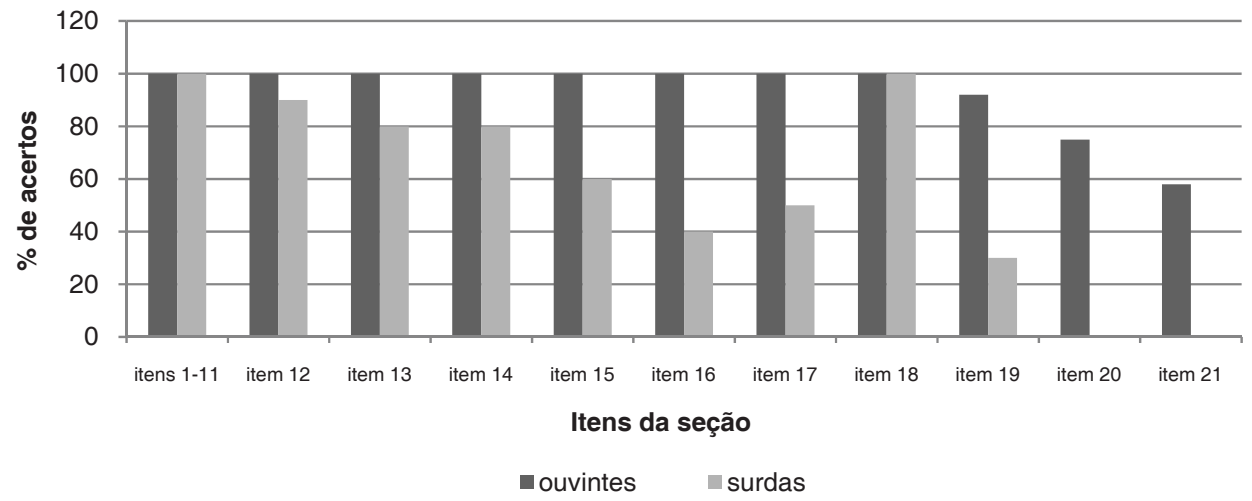

Figura 1 - Respostas das crianças ouvintes e surdas implantadas para seção Estrutura

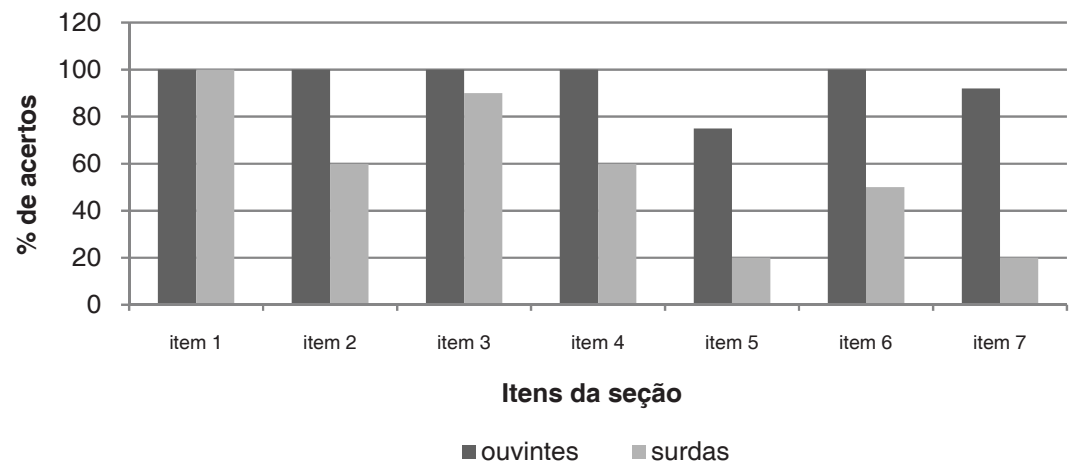

Figura 2 - Respostas das crianças ouvintes e surdas implantadas para seção Vocabulário-Objetos

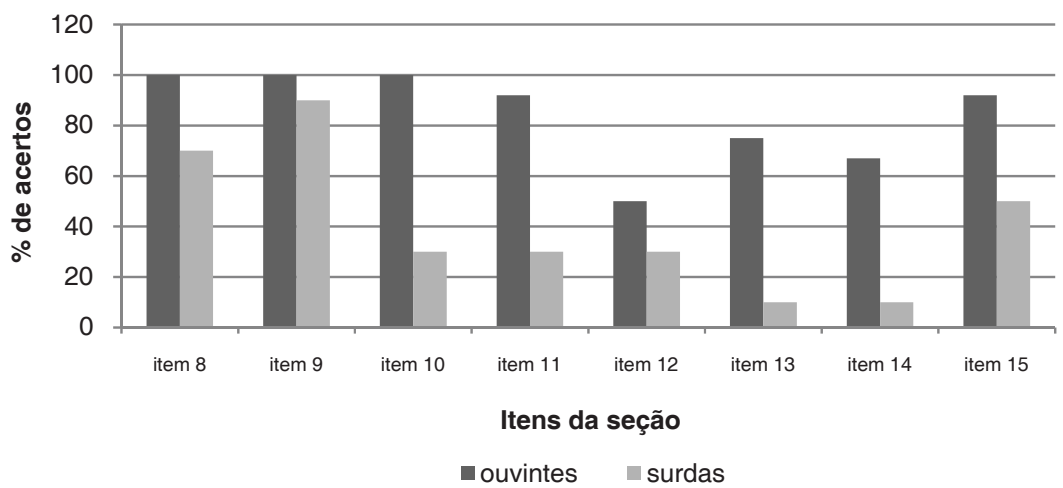

Figura 3 - Respostas das crianças ouvintes e surdas implantadas para seção Vocabulário-Figuras

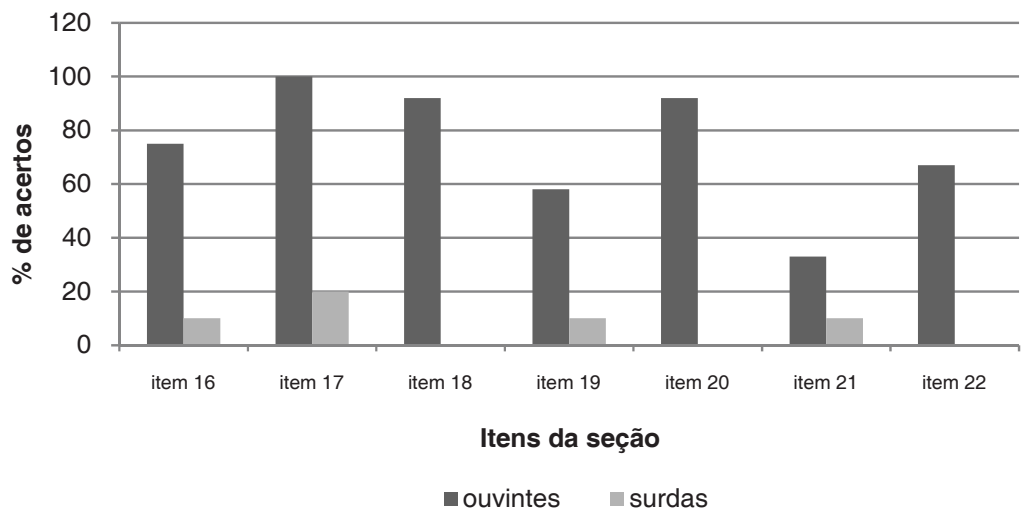

Figura 4 - Respostas das crianças ouvintes e surdas implantadas para seção Vocabulário-Palavras 
Para o subteste Figuras, de acordo com a Figura 3 , os itens em que ocorreu o maior número de acertos pelas crianças surdas $(90 \%$ e $70 \%$, respectivamente) foram: item 9 (flor) e item 8 (cadeira). Estes itens foram uns dos únicos que todas as crianças ouvintes acertaram. Nove crianças surdas $(90 \%)$ falharam nos itens 13 (homens) e 14 (chovendo). Estes foram itens em que ocorreram maior número de falhas pelas crianças ouvintes. Houve acerto de apenas 3 crianças surdas (30\%) nos itens $10,11 \mathrm{e}$ 12. Nos itens 10 e 11, a maioria das crianças ouvintes acertou ( $100 \%$ e $90 \%$, respectivamente), porém, no item 12 (cartas), o índice de falhas das crianças surdas e ouvintes foi próximo. Houve $100 \%$ de acerto das crianças ouvintes somente para os itens 8, 9 e 10.

Na seção Vocabulário, subteste Palavras (Figura 4), duas crianças surdas foram capazes de realizar esta prova. Uma delas apresentou respostas semeIhantes às das crianças ouvintes nos itens 16,17, 19 e 21. A outra, realizou apenas o item 17, negandose realizar os demais. Houve $100 \%$ de acerto das crianças ouvintes somente para o item 17.

As Figuras 5, 6 e 7 apresentam os gráficos comparativos dos dois grupos de participantes para a seção Conteúdo. O gráfico da Figura 5 mostra os resultados obtidos pelas crianças, surdas implantadas e ouvintes, para a descrição da Figura 2. A Figura 6 compara os resultados obtidos pelas crianças surdas e ouvintes na descrição da Figura 3. O gráfico da Figura 7 compara os resultados obtidos pelas crianças surdas implantadas e ouvintes para a descrição da Figura 4. É importante destacar que Figura 1 foi utilizada apenas para treino e não foi pontuada.

Observou-se, por meio das figuras, que os resultados das crianças implantadas foram inferiores ao dos seus pares ouvintes. A maioria das crianças surdas apresentou resposta Basal A (referência a aspectos específicos da figuras apresentadas), mas em todas as figuras pelo menos uma criança apresentou resposta Basal B (referência à figura como um todo). Quanto às Ideias Conectadas, obteve-se maior uso de IC-B (frases de 3 ideias conectadas) pelas crianças surdas que realizaram essa prova. $O$ resultado foi semelhante ao apresentado por algumas crianças ouvintes. Nenhuma criança surda, porém, utilizou IC-D, como observado com as ouvintes. Para Sentenças Adicionais, os resultados obtidos foram tanto SA-A quanto SA-B. As crianças ouvintes apresentaram predominantemente SA-B.

De forma geral, três crianças demonstraram bom desempenho nesta prova, verbalizando pensamentos conectados, sem serem demasiadamente repetitivas quando comparadas às crianças ouvintes, e utilizando a linguagem criativamente.

Salienta-se que a falta de inteligibilidade de fala das crianças surdas prejudicou a compreensão da avaliadora para análise dos dados dessa seção,

As Tabelas 1 e 2 apresentam as pontuações obtidas por cada criança ouvinte e surda implantada. A Tabela 2 apresenta também a idade, o tempo de perda auditiva e o tempo de uso de IC, para melhor visualização.

Verifica-se que a pontuação das crianças ouvintes variou entre 13 e 50 pontos, tendo-se como média geral a pontuação 28 . As pontuações obtidas pelas crianças ouvintes avaliadas variaram entre 51 e 61 (média -56). Pôde-se constatar que todas as crianças apresentaram um desempenho quantitativamente inferior ao das crianças ouvintes. A criança 6 , todavia, obteve um desempenho próximo ao de uma criança ouvinte.

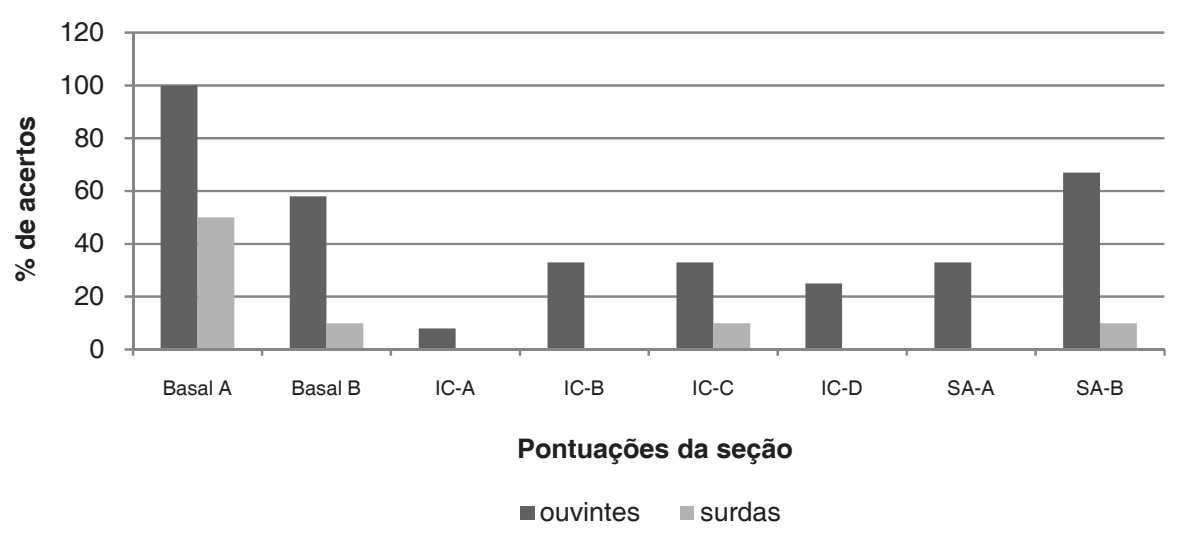

Figura 5 - Respostas das crianças ouvintes e surdas implantadas para seção Conteúdo-Fig.2 


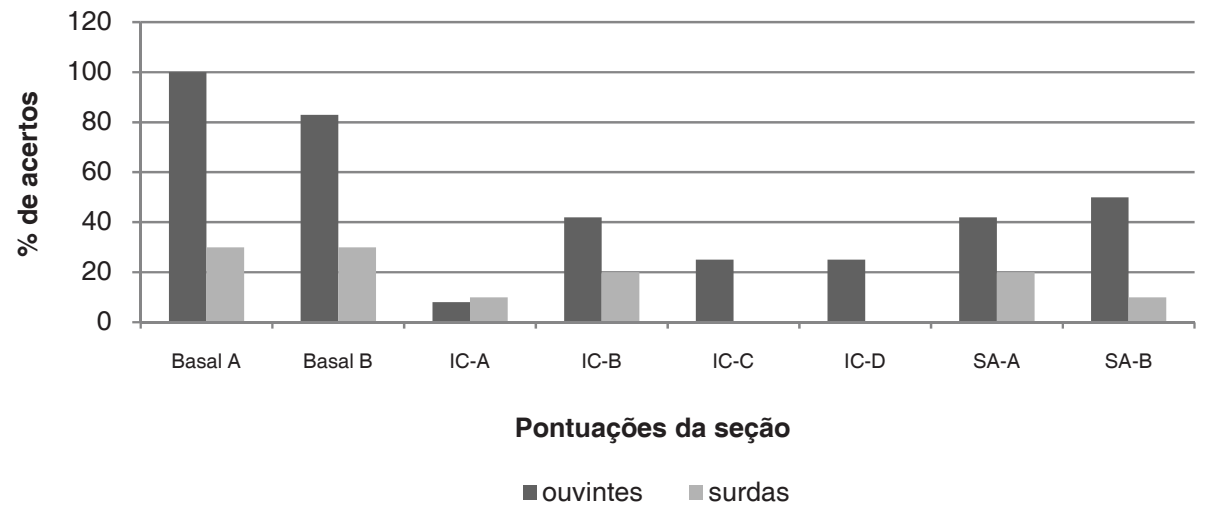

Figura 6 - Respostas das crianças ouvintes e surdas implantadas para seção Conteúdo-Fig.3

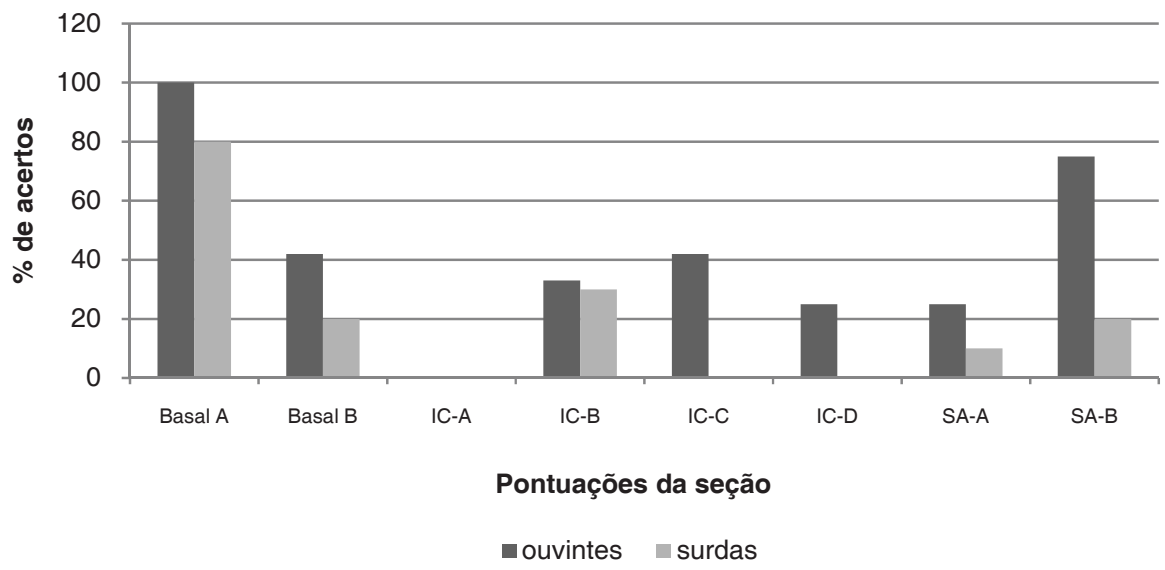

Figura 7 - Respostas das crianças ouvintes e surdas implantadas para seção Conteúdo-Fig.4

Tabela 1 - Pontuações obtidas pelas crianças ouvintes na Escala de Expressão Verbal

\begin{tabular}{cccccc}
\hline Participantes & Idade & $\begin{array}{c}\text { Estrutura } \\
\text { (PT=21) }\end{array}$ & $\begin{array}{c}\text { Vocabulário } \\
\text { (PT=22) }\end{array}$ & $\begin{array}{c}\text { Conteúdo } \\
\text { (PT=24) }\end{array}$ & $\begin{array}{c}\text { Total } \\
\text { (PT=67) }\end{array}$ \\
\hline 1 & $4: 2$ & 20 & 18 & 18 & 56 \\
2 & $4: 2$ & 18 & 15 & 18 & 51 \\
3 & $4: 3$ & 21 & 19 & 14 & 54 \\
4 & $4: 4$ & 21 & 20 & 19 & 60 \\
5 & $4: 5$ & 20 & 19 & 22 & 61 \\
6 & $4: 5$ & 21 & 16 & 19 & 56 \\
7 & $4: 6$ & 21 & 20 & 13 & 54 \\
8 & $4: 6$ & 21 & 18 & 15 & 53 \\
9 & $4: 7$ & 21 & 19 & 19 & 59 \\
10 & $4: 9$ & 19 & 16 & 17 & 52 \\
11 & $4: 10$ & 20 & 17 & 20 & 57 \\
12 & $4: 11$ & 21 & 17 & 18 & 56 \\
\hline
\end{tabular}

* PT: pontuação total para o teste 
Tabela 2 - Pontuações obtidas pelas crianças surdas na Escala de Expressão Verbal

\begin{tabular}{cccccccc}
\hline $\begin{array}{c}\text { Partici- } \\
\text { pantes }\end{array}$ & Idade & $\begin{array}{c}\text { Tempo de } \\
\text { surdez }\end{array}$ & $\begin{array}{c}\text { Tempo de } \\
\text { uso do IC }\end{array}$ & $\begin{array}{c}\text { Estrutura } \\
\text { (PT=21) }\end{array}$ & $\begin{array}{c}\text { Vocabulário } \\
\text { (PT=22) }\end{array}$ & $\begin{array}{c}\text { Conteúdo } \\
\text { (PT=24) }\end{array}$ & $\begin{array}{c}\text { Total } \\
\text { (PT=67) }\end{array}$ \\
\hline 1 & $4: 3$ & $2: 10$ & $1: 5$ & 19 & 14 & 10 & 43 \\
2 & $4: 5$ & $3: 2$ & $1: 3$ & 18 & 4 & - & 22 \\
3 & $4: 6$ & $3: 5$ & $1: 1$ & 15 & 5 & 3 & 23 \\
4 & $4: 6$ & $2: 9$ & $1: 7$ & 15 & 8 & 1 & 24 \\
5 & $4: 7$ & $4: 0$ & $0: 7$ & 12 & 1 & - & 13 \\
6 & $4: 8$ & $2: 0$ & $2: 8$ & 19 & 14 & 17 & 50 \\
7 & $4: 9$ & $3: 6$ & $1: 3$ & 17 & 8 & 1 & 26 \\
8 & $4: 10$ & $2: 8$ & $2: 2$ & 19 & 11 & 11 & 41 \\
9 & $5: 0$ & $3: 7$ & $1: 5$ & 12 & 5 & 1 & 18 \\
10 & $5: 0$ & $3: 8$ & $1: 4$ & 16 & 7 & 2 & 25 \\
\hline
\end{tabular}

* PT: pontuação total para o teste

\section{DISCUSSÃO}

Há algumas décadas, a linguagem oral era uma forma de expressão praticamente inatingível para grande parte das pessoas com surdez profunda. Com os avanços da tecnologia, o implante coclear tem possibilitado a aquisição da linguagem oral na surdez. Pôde-se perceber essa aquisição pelos resultados apresentados nesta pesquisa, que mostram as similaridades e as dificuldades de crianças surdas implantadas quando comparadas aos seus pares ouvintes.

Os primeiros resultados expressos dizem respeito à estrutura da linguagem das crianças surdas implantadas e das crianças ouvintes. Tendo em foco a linguagem oral das crianças surdas, notouse a preponderância das denominadas palavras de "conteúdo", a saber, substantivos e verbos, e a escassez de palavras de "função", como conjunções, verbos auxiliares, preposições e pronomes, conforme descrição da literatura para estudos com indivíduos pré-linguisticamente surdos. Autores descrevem a fala desses indivíduos como telegráfica, devido ao uso inadequado de preposições e omissão de conectivos de menor carga semântica, sendo incomuns as sentenças combinadas e complexas ${ }^{14,15}$. As afirmações dos autores podem ser notadas por meio da Figura 1, que demonstra facilidade de exibir os itens de 1-11, 12-14 e 18, referentes à expressão de palavras de "conteúdo" e dificuldade nos demais itens como 16 (uso de preposições), 17 (uso de pronomes), 21 (uso de orações complexas), apesar de algumas crianças surdas utilizarem sentenças combinadas.

Destaca-se que a seção "Estrutura" da Escala de Expressão da RDLS enfatiza mais o aspecto sintático e dá pouca ênfase aos aspectos fonético-fono- lógico e morfológico. Notou-se que, sintaticamente, os resultados obtidos por algumas crianças surdas implantadas, foram próximos aos obtidos por algumas crianças ouvintes, entretanto, a ininteligibilidade de fala, devido às alterações fonéticas-fonológicas, foi muito frequente durante as avaliações. Se esses aspectos fossem avaliados especificamente é provável que as crianças surdas obtivessem um resultado bem inferior ao das ouvintes.

O desenvolvimento da fonologia e a articulação são inegavelmente afetados pela surdez em indivíduos pré-linguisticamente surdos, como é o caso da maioria dos participantes deste estudo. As dificuldades experimentadas pelos surdos para desenvolver uma fala inteligível indicam que, nas crianças ouvintes, o desenvolvimento da fonologia e a precisão fonética são alcançados basicamente por meio de recursos auditivos, apesar da percepção visual dos movimentos da fala colaborar na aquisição dos fonemas em crianças com audição e visão normais. A ininteligibilidade das crianças surdas pode ser explicada, pelo menos em parte, por uma fonologia incompleta e, em alguns casos por imprecisão fonética ${ }^{5,15}$.

Um estudo comparativo entre crianças implantadas com idade cronológica de seis anos e seus pares ouvintes mostrou pontuações similares para a prova de estrutura da Escala de Expressão da RDLS. O tempo de uso do IC das referidas crianças variou entre dois anos e seis meses e cinco anos, tempo superior ao das crianças dessa pesquisa. Isso pode significar que, a linguagem oral das crianças implantadas evolui conforme o tempo de uso, ou seja, conforme a idade auditiva aumenta ${ }^{16}$. Um estudo brasileiro com 60 crianças usuárias de IC mostrou que o tempo de uso do mesmo, dentre 
outras variáveis, é estatisticamente significante ao desempenho da linguagem oral ${ }^{17}$.

Os resultados obtidos para a seção "Vocabulário" foram expressos nas Figuras 2, 3 e 4 . Observase que os itens 5 e 7 foram os únicos que as crianças ouvintes falharam. Isso se deve ao fato desta pesquisa ter sido realizada antes da adaptação da RDLS no Brasil. Até então, os itens 5 e 7 eram referentes às palavras "escova" e "xícara". O alto índice de falhas nesses itens deve-se ao fato de muitas crianças utilizarem os termos "pente" e "copo" à "escova" e "xícara". Esse foi um dos motivos que justificou a alteração dos termos na adaptação do teste para o português brasileiro ${ }^{4}$.

Os itens referentes a verbos (11 e 14), são considerados difíceis para as crianças surdas, conforme descrito no manual americano da RDLS ${ }^{3}$. Portanto, as falhas nesses itens eram previstas. $50 \%$, ou seja, 5 crianças acertaram o item 15. Em contrapartida, neste item apenas uma criança ouvinte falhou.

Analisando a seção Vocabulário, subteste Palavras (Figura 4), pode-se afirmar que as crianças surdas apresentaram dificuldades em utilizar a linguagem interna, ou seja, pensar e refletir através da linguagem, para consequentemente, compreender situações que vão além do "aqui e agora", além do concreto. Pode-se afirmar ainda, diante disso, que descrever ou definir os conceitos solicitados nessa seção é, sem dúvida, uma habilidade bastante refinada e complexa para crianças implantadas. É possível que melhores resultados sejam encontrados com crianças com maior tempo de uso. Em estudo com 19 crianças usuárias de IC por cinco anos, avaliadas com as Escalas Reynell, os resultados foram semelhantes. Segundo as autoras, embora as crianças consigam realizar as atividades de nomeação de objetos e figuras, apresentaram grande dificuldade para descrever o significado de uma palavra ${ }^{18}$.

De acordo com a Figura 4, todavia, o subteste Palavras, por ser uma prova abstrata, foi difícil de ser realizada inclusive pelas crianças ouvintes. Observou-se, portanto, um desempenho inferior das crianças surdas quando comparadas às ouvintes, mas também a dificuldade das ouvintes em alguns itens da seção. É interessante constatar também que a criança surda que obteve êxito na seção, acertou três itens nos quais as crianças ouvintes mais falharam: 16, 19 e 21. Além disso, o item 17, também respondido pela criança surda em questão, foi o item no qual todas as crianças ouvintes acertaram.

De acordo com pesquisas do aspecto semântico em crianças pré-linguisticamente surdas, o vocabulário das mesmas é escasso e retardado, contendo menos palavras abstratas e mais palavras concretas ${ }^{15}$. A dificuldade com o uso de palavras abstratas foi comprovada nos subtestes posteriores a esta seção, porém essa dificuldade foi averiguada nas crianças ouvintes, avaliadas nessa pesquisa, também. Pode-se dizer, por meio dos resultados obtidos nessa pesquisa, que o vocabulário é "retardado", ou seja, "atrasado" ou inferior ao das crianças ouvintes da mesma faixa etária, porém é possível que seja relativo à sua "idade auditiva". Além disso, um estudo longitudinal recente mostrou que o vocabulário de crianças surdas, que possuem uso contínuo do implante coclear, evolui ao longo do tempo ${ }^{19}$.

Analisando as Figuras 5, 6 e 7, notou-se os resultados inferiores das crianças surdas implantadas comparados aos resultados de seus pares ouvintes para a seção "Conteúdo", ou seja, as crianças surdas expressaram menos informações referentes às figuras, um menor numero de conexões de ideias e de sentenças relativas a elas. Conforme já mencionado, a falta de inteligibilidade de fala das crianças surdas prejudicou a compreensão da avaliadora, podendo ter prejudicado também a análise do desempenho verbal pela mesma.

Em estudo comparativo de crianças implantadas e ouvintes com 6 e 7 anos de idade, os resultados obtidos pela metade das crianças implantadas foram inferiores aos obtidos pelas crianças ouvintes para a prova de Conteúdo da RDLS. Observou-se que as crianças ouvintes utilizaram maior número de ideias conectadas e de sentenças adicionais que as crianças implantadas. As últimas produziram frases simples e com menos ideias que as das crianças ouvintes ${ }^{20}$.

Observando as Tabelas 1 e 2, verifica-se um melhor desempenho das participantes 1,6 e 8 . Nota-se que as crianças 6 e 8 são as que apresentam menor tempo de privação sensorial e maior tempo de uso de IC, confirmando que quanto menor o tempo de surdez, melhor o prognóstico do IC e, consequentemente o desempenho da linguagem. Resultados semelhantes foram obtidos com crianças implantadas de 6 a 7 anos de idade cronológica, quando comparada a expressão verbal com os resultados de seus pares ouvintes ${ }^{20}$.

Em estudo com crianças brasileiras, usuárias de IC há 5 anos, foi encontrada correlação estatisticamente significante entre o tempo de privação sensorial e a pontuação na subescala de conteúdo da escala de expressão da RDLS ${ }^{18}$. Os resultados indicam que quanto menor o tempo de privação sensorial, melhor é o desempenho das crianças $16,17,21$.

É importante considerar que as crianças deficientes auditivas já apresentam um atraso de linguagem significante em relação à criança ouvinte 
quando recebem o IC. Isto explica o déficit que as mesmas apresentam em relação aos seus pares e evidencia que período de privação sensorial deve o menor possível, já que neste período as estruturas neurais podem degenerar facilmente, comprometendo o desenvolvimento da linguagem ${ }^{13,17}$.

O desempenho de audição e de linguagem de crianças surdas, usuárias de implante coclear multicanal, é influenciado por diversos aspectos. Pesquisa recente sobre o assunto mostrou que as categorias auditivas, a idade da criança na avaliação, o tempo de privação sensorial e o tempo de uso do dispositivo foram estatisticamente significantes. Quanto às categorias de linguagem, foram constatados resultados significantes para os aspectos idade e tempo de uso do implante coclear ${ }^{17}$. Apesar do tempo de privação sensorial não ter sido estatisticamente significante na pesquisa anteriormente citada, autores destacam que este aspecto tem sido apontado como um dos mais relevantes na literatura, conforme já mencionado anteriormente.

A literatura destaca que as crianças implantadas aprendem a linguagem no mesmo ritmo ou superior de seus pares ouvintes, todavia o prejuízo ou atraso linguístico em relação a eles pode permanecer. Este atraso linguístico não aumenta com o passar do tempo, o que geralmente ocorre com as crianças surdas não implantadas ${ }^{13}$.

Estudos longitudinais são importantes para averiguar o desenvolvimento da linguagem expressiva das crianças implantadas. É importante mencionar que, apesar das crianças surdas implantadas apresentarem resultados inferiores aos das ouvintes, a expressão verbal das mesmas evolui quando elas utilizam o dispositivo eletrônico sistematicamente ${ }^{4}$.
De acordo com alguns pesquisadores, crianças implantadas antes dos dois anos, podem apresentar alteração no desenvolvimento da linguagem, todavia, com o passar do tempo de uso do IC, é possível que a criança alcance o desenvolvimento da linguagem de uma criança ouvinte de mesma idade cronológica ${ }^{22,23}$.

Crianças surdas com IC e sem IC foram avaliadas longitudinalmente. Os resultados obtidos pelas crianças com implante por meio das Escalas Reynell mostraram uma regressão por idade. Elas obtiveram metade ou menos da metade dos resultados obtidos pelos seus pares ouvintes. A média do desenvolvimento da linguagem para a compreensão das crianças implantadas no primeiro ano de uso do IC foi equivalente ao das crianças ouvintes ${ }^{24}$.

Sem dúvida, o objetivo final do implante coclear é desenvolvimento da linguagem oral, entretanto, há muito a ser pesquisado a respeito do desenvolvimento de linguagem da criança implantada.

\section{CONCLUSÃO}

Os resultados obtidos pelas crianças deficientes auditivas, usuárias de IC, foram inferiores aos seus pares ouvintes. As crianças surdas que apresentaram as maiores pontuações na Escala de Expressão da RDLS foram as que possuíam maior tempo de uso do IC e menor tempo de privação sensorial.

\section{AGRADECIMENTOS}

À CAPES, pelo apoio financeiro concedido.

\begin{abstract}
Purpose: to analyze and compare the verbal expression of children without hearing impairment and deaf children using cochlear implants. Methods: the participants were twelve children without hearing impairment, with ages between four years two months and four years eleven months and ten deaf children using cochlear implants with age between four years and three months and five years and zero months. The children were evaluated using the Verbal Expression Scale of Reynell Developmental Language Scales (RDLS), American version, adapted by Fortunato-Queiroz (2007). The data of the two groups of children were analyzed and compared. Results: the deaf children had a worse performance when compared to the children without hearing impairment. Three deaf children had results that approximate the results of the children without hearing impairment, accepted as normal standard in this work. Conclusion: the results of the deaf children using cochlear implants were inferiors yours pairs listeners. The deaf children who showed the biggest punctuations were the ones with shorter time of hearing sense deprivation and longer time using the cochlear implant.
\end{abstract}

KEYWORDS: Cochlear Implantation; Language Development; Deafness 


\section{REFERÊNCIAS}

1. Bess FH, Humes LE. Fundamentos de audiologia. 2. ed. Porto Alegre: Artes Médicas; 1998.

2. Mondelli MFCG, Blasca WQ. Processo de adaptação de aparelhos de amplificação sonora individual: teorias e técnicas norteadoras. Fono Atual. 2000; (12):16-20.

3. Reynell JK, Gruber CP. Reynell developmental language scales. Los Angeles: Western Psychological Services; 1990.

4. Fortunato-Queiroz CAU. Reynell Developmental Language Scales (RDLS): um estudo longitudinal em crianças usuárias de implante coclear. [tese] São Carlos (SP): Universidade Federal de São Carlos; 2007.

5. Santana AP. O processo de aquisição da linguagem: estudo comparativo de duas crianças usuárias de implante coclear. Disturb Comun. 2005; 17(2):233-43.

6. Moraes TV, Zeigelboim BS, Bevilacqua MC, Jacob LC. Indicação de implante coclear: tendências atuais. Acta Awho. 2001; 20(4):229-37.

7. Harrison RV, Gordon KA, Mount RJ. Is there a critical period for cochlear implantation in congenitally deaf children? Analyses of hearing and speech perception performance after implantation. Develop Psychobiol. 2005; 46(3):252-61.

8. Nicholas JG, Geers AE. Effects of early auditory experience on the spoken language of deaf children at 3 years of age. Ear Hear. 2006; 27(3):286-98.

9. Nicholas JG, Geers AE. Will they catch up? The role of age at cochlear implantation in the spoken language development of children with severe to profound hearing loss. J Speech Lang Hear Res. 2007; 50(4):1048-62.

10. Mylanus E, Vermeulen A, Neijenhuis K, Snik A. Auditory and language assessment tools in pediatric cochlear implant patients: a follow-up study. In: Abstracts of the $8^{\mathrm{a}}$ European Symposium Pediatric Cochlear Implants; 2006 Mar 25-28; Palazzo del Cinema. Lido di Venezia; 2006. p.106.

11. Moret ALM, Ficker LB, Martinez MANS. Fórum de (Re)habilitação auditiva/ 2000: XV Encontro Internacional de Audiologia. Dist Comun. 2000; 11(2):339-48.

12. Nikolopoulos TP, Archbold SM, Gregory S. Young deaf children with hearing aids or cochlear

\section{RECEBIDO EM: 02/12/2008 \\ ACEITO EM: 24/06/2009}

Endereço para correspondência:

Carla Aparecida de Urzedo Fortunato

Rua Zina Olga Caldo Donato, 525

Ribeirão Preto - SP

CEP: $14065-260$

E-mail: caurzedo@yahoo.com implants: early assessment package for monitoring progress. Int J Pediatr. Otorhinolaryngol. 2005; 69(2):175-86.

13. Robbins AM. Language developmental. In: Waltzman SB, Cohen NL. Cochlear implants. New York: Thieme; 2000. p.269-92.

14. Lima MCMP. Avaliação de fala de lactentes no período pré-linguístico: uma proposta para triagem de problemas auditivos. [tese] Campinas (SP): Universidade de Campinas; 1997.

15. Mogford K. Aquisição da linguagem oral no indivíduo pré-linguisticamente surdo. In: Bishop D, Mogford K. Desenvolvimento da linguagem em circunstâncias excepcionais. Rio de Janeiro: Revinter; 2002. p.145-77.

16. Fortunato-Queiroz CAU, Costa MPR, Bevilacqua M.C. Análise comparativa da expressão verbal de crianças ouvintes e surdas implantadas. In: Anais de Eventos da UFSCar: 6a. Jornada Científica da UFSCar; 2005 Out 10-14, São Carlos-SP. São Carlos: UFSCar; 2005. p.1215-6.

17. Moret ALM, Bevilacqua MC, Costa OA. Implante coclear: audição e linguagem em crianças deficientes auditivas pré-linguais. Pró-Fono. 2007; 19(3):295-304.

18. Stuchi RF, Nascimento LT, Bevilacqua MC, Brito Neto RV. Linguagem oral de crianças com cinco anos de uso do implante coclear. Pró-Fono. 2007; 19(2):167-76.

19. Fortunato-Queiroz CAU, Costa MPR, Bevilacqua MC. A evolução do vocabulário de crianças surdas usuárias de implante coclear In: Almeida MA, Mendes EG, Hayashi MCPI. Temas em Educação Especial: deficiências sensoriais e deficiência mental. Araraquara: Junqueira \& Marin Editores; 2008. p. 176-84.

20. Fortunato-Queiroz CAU, Costa, MPR, Bevilacqua MC. Crianças surdas implantadas entre 6 e 7 anos de idade: avaliando a Expressão Verbal. In: Almeida MA, Mendes EG, Hayashi MCPI. Temas em Educação Especial: Conhecimentos para fundamentar a prática. Araraquara: Junqueira \& Marin, 2008, p. 360-72.

21. Miyamoto RT, Kirk KI, Svirsky MA, Sehgal ST. Communication skills in pediatric cochlear implant recipients. Acta Otolaryngol. 1999; 119(2):219-24.

22. Colletti V, Carner M, Miorelli V, Guida M, Colletti L, Fiorino FG. Cochlear implantation at under 12 months: report on 10 patients. Laryngoscope. 2005; 115(3):445-9.

23. Manrique M, Cervera-Paz FJ, Huarte A, Molina M. Advantages of cochlear implantation in prelingual deaf children before 2 years of age when compared with later implantation. Laryngoscope. 2004; 114(8):1462-9.

24. Robbins AM, Svirsky M, Kirk KI. Children with implants can speak, but can they communicate? Otolaryngol Head Neck Surg. 1997; 117(3Pt1):155-60. 